\title{
POESIA E CONHECIMENTO
}

\section{POETRY AND KNOWLEDGE}

Vera Lúcia de OLIVEIRA ${ }^{1}$

RESUMO: 0 texto trata da especificidade da linguagem poética, capaz de unir elementos contraditórios da realidade por sua capacidade de síntese e condensação. A poesia proporciona uma forma de conhecimento interior complexa e profunda, complementar e, em muitos casos, alternativa às categorias racionais do pensamento.

PALAVRAS-CHAVE: Poesia; Poética; Filosofia; Teoria da literatura; Linguística.

ABSTRACT: The main purpose of this paper is to deal with the speciticity poetic language, which is capable of stablishing a relation among contradictory elements of reality through their synthesis and condensation. Thus, poetry provides a complex and deep form of knowledge, which is complementary and, in many cases, alternative to rational categories of thought.

KEYWORDS: Poetry; Poetics; Phylosophy; Theory of Literature; Linguistics.

\footnotetext{
${ }^{1}$ Departamento de Filosofia, Linguistica e Literaturas, Facoltà di Lettere e Filosofia, Università degli Studi di Perugia (UNIPG), 06135, Perugia, Itália, e-mail: veralucia.deoliveira.m@gmail.com
} 
"A beleza não é palpável sem as palavras. Coisas e palavras sangram pela mesma ferida."

Octavio Paz

Na conferência Da cegueira colectiva à aprendizagem da insensibilidade, proferida na Universidade Mondlane, em Maputo, o escritor Moçambicano Mia Couto, falando sobre a importância da literatura e da poesia, narra um episódio da vida de Nelson Mandela. Encarcerado durante vinte e sete anos por seu sonho de um país independente e livre, onde houvesse tolerância e respeito entre brancos e negros, Mandela lê um dia o poema "Invictus" (1875), do poeta britânico Willian Ernest Henley, cujos últimos versos recitam: "Não importa se a passagem é estreita / Não importa quantos castigos devo penar / Eu sou o dono do meu destino / Eu sou o capitão da minha vida". Esse poema vai se imprimir na consciência e na alma de Mandela, em um momento de grande dificuldade, ajudando-o a superar rancores, ódios, privações, castigos. Afirma Mia Couto:

Estes versos, meus amigos, foram uma espécie de suporte moral que deram força a Nelson Mandela. Vezes infinitas o prisioneiro 46664 da Ilha de Robin regressou a estes versos para não sucumbir. Como escritor e poeta, dá-me grande alegria saber deste poder da poesia. (...) 0 seu autor não foi um poeta sul -africano, não foi sequer um poeta africano. (...) Estes versos viajaram para além de séculos e continentes e iluminaram a esperança de um homem que, em vez de se vitimizar e procurar a vingança, nos deu uma eterna lição de crença nos outros (MIA COUTO, 2012).

Pois bem, se a poesia tem esse poder de salvar e preservar a parte melhor de um homem, mesmo submetido às piores privações, de onde vem essa sua capacidade? 0 que é a poesia, como defini-la, entendê-la e explicá-la? Qual a sua substância mais íntima, a sua dimensão e essência, a sua matéria, a sua especificidade em relação à linguagem? Posto que poesia é linguagem.

A essas e outras perguntas buscaram responder, ao longo dos sécu- 
los, poetas, filósofos e teóricos da literatura. No livro $O$ que é a poesia, Edson Cruz (2009) propõe essas mesmas questões a quarenta e cinco diferentes poetas brasileiros contemporâneos e não há, ali, duas respostas idênticas.

Há algo de fundamental e enigmático no ser humano, que precisa da linguagem poética e de sua estrutura para se configurar. Na poesia, há elementos complexos e contraditórios, nos quais concreto e abstrato se unem, racional e intuitivo convivem,os nomes e as coisas se buscam, marcando encontro em uma dimensão que é, ao mesmo tempo, tangível e telúrica, impalpável e imaterial. A poesia é a arte de ver, afirma Lêdo Ivo, "a arte de ver e saber ver o que, mesmo sob os nossos olhos, só pode ser distinguido pelo uso da iluminação da linguagem"(IVO, 2011, p. 12). E acrescenta ainda que "há algo, no mundo e sobre o mundo, que só a linguagem poética tem condições de dizer" (2011,p. 13).

No âmbito desse trabalho, seguiremos alguns entre os mais representativos poetas e intelectuais que se debruçaram sobre o mistério da poesia, reunindo, na segunda parte, cujo título é Poéticas, uma breve antologia de líricas portuguesas e brasileiras, que são, a partir de várias perspectivas e formas, declarações de poéticas por parte dos seus autores.

\section{Poética}

Poesia é linguagem, consiste de linguagem, embora produza efeitos que a linguagem comum não consegue produzir. Em que estaria essa diferença em relação às demais formas de linguagem? Afirma Samuel R. Levin (1975), em seu livro Estruturas linguísticas em poesia, que, "em oposição à prosa, a poesia se distingue por uma singular unidade de estrutura", ou seja, na poesia, "a forma do discurso e seu significado se amalgamam numa unidade superior" (LEVIN, 1975, p. 13). Segundo esse princípio de equivalência, todos os elementos fonéticos do poema, como rima, assonância, aliteração, paranomásia, onomatopéia e outros, estão em íntima relação entre si e em correlação com os elementos se- 
mânticos, como metáforas, metonímias, sinédoques, hipérboles, antíteses, oxímoros, etc. Isso leva a poesia a permanecer na memória do leitor (LEVIN, 1975, p. 13-14).

Também para Roman Jakobson (1977), a poesia nasce de uma complexa disposição rítmica, da seleção e combinação das palavras em uma sequência dominada pelo princípio da equivalência, ou seja, pela íntima relação semântica e fonética dos signos (JAKOBSON, 1977, p. 118-162). Daqui deriva a conclamada dificuldade da tradução poética, que não se trata de transposição, em outra língua, de um conteúdo específico, mas de recriação de formas plasmadas por suas substâncias e indissoluvelmente unidas.

Se a poesia é linguagem, ela parece ser, no entanto, um corpo estranho nas artes da palavra e está, por sua estrutura e significação, mais próxima da música e das artes plásticas, pois, como estas, põe em correlação o racional, o irracional, a compreensão cognitiva, a experiência intuitiva e, até mesmo, a contemplação mística (PIGNATARI, 1977; JOLY, 2005).

Sartre (2002) afirma que os poetas utilizam as palavras como se fossem coisas e, de fato, no poema, a linguagem tenta superar a distância que a separa do objeto que ela representa, tenta incorporar formas e aspectos característicos do mesmo. Para o poeta português Nuno Júdice (1998), isso se dá porque “o poema produz imagens”, ou seja, "há uma intenção concreta, visual, na construção do poema que faz com que ele se distingua do texto abstracto"(JÚDICE, 1998, p. 24), como poder ser, por exemplo, o texto filosófico. Por outro lado, Alfredo Bosi (1977) acrescenta que a experiência da imagem é anterior à da palavra e se enraiza diretamente no corpo: "A imagem é um modo da presença, que tende a suprir o contacto direto e a manter, juntas, a realidade do objeto em si e a sua existência em nós" (BOSI, 1977, p. 13).

0 poeta sabe que a palavra não é a coisa, mas, no poema, a palavra quer ser a coisa, torna-se a coisa. Isso ocorre também pelo processo de desautomatização da linguagem que o poema realiza. Para Octavio Paz (1982), 
[...] a criação poética se inicia como violência sobre a linguagem. 0 primeiro ato dessa operação consiste no desenraizamento das palavras: separadas do mundo informativo da fala, os vocábulos se tornam únicos, como se acabassem de nascer(PAZ, 1982, p. 47).

Na poesia, as palavras têm volume, peso, sabor, cheiro e, nesse sentido, cada poema cria uma lógica e uma gramática própria. Sendo assim, no poema o signo não é arbitrário, ao contrário, ele congrega em si a energia originária de verbo com o qual designamos o mundo. No Gênesis (Gen.2, 10-20), sabemos que o primeiro homem, Adão, recebeu de Deus o privilégio de atribuir um nome a cada elemento do Jardim do Éden. 0 poeta mantém essa relação primeira, concreta e física, com as palavras, pois elas - pela imagem - transcendem a linguagem, passam a uma condição híbrida, concreta e abstrata ao mesmo tempo. As palavras, além disso, são veiculadas pela voz e pelo corpo e, avulsas do contexto humano, são mensagens que se perdem sem possibilidade de decodificação.

A poesia carrega consigo, desde sempre, um halo de mistério e fascinação. Convive pelo seu poder de encantamento, com as fórmulas da magia e já esteve subordinada ao culto, consagrada, em várias culturas, à exaltação da divindade (SPINA, 2002, p. 26-27). Em algumas civilizações antigas, a figura do poeta se confundia com a do vidente, do profeta, do adivinho. A poesia e a música certamente nasceram associadas à magia e à religião, mas não derivam delas, pois o "sentimento estético preexiste a essas atividades: é no homem natural e inato" (SPINA, 2002, p. 36).

A figura do poeta se alterna, assim, entre duas polaridades: ora é visto como um ser tomado por possessão, que, em estado de alteração e êxtase, cria o poema violando regras e preceitos; ora é considerado um artesão que, com lucidez e disciplina, domina as formas e a substância do poético (AGUIAR E SILVA, 1976, p. 162). Cada período histórico elegeu uma dessas duas figurações, em consonância com as ideias e o papel que se atribuía à arte e à literatura em geral.

Para alguns poetas, a poesia ainda mantém esse significado visioná- 
rio e divinatório; com isso, a própria inspiração, ou o que chamamos de inspiração (que pode ser definido de muitas formas: inconsciente, transporte emotivo, estado místico, transe), é vivida por muitos como uma experiência mística, um estado de transe ou de graça, Assim é para Manuel Bandeira:

Na minha experiência pessoal fui verificando que o meu esforço consciente só resultava em insatisfação, ao passo que o que me saía do subconsciente, numa espécie de transe ou alumbramento, tinha menos a virtude de me deixar aliviado de minhas angústias. Longe de me sentir humilhado, rejubilava, como se de repente me tivessem posto em estado de graça (BANDEIRA, 1984, p. 30).

Outros recusam esse elemento, afirmando que a poesia é técnica e substância plasmada conscientemente, elaborada palavra por palavra, ou, como propõe João Cabral de Melo Neto (1998), tijolo por tijolo, numa construção humana que é fruto da razão:

A verdade é que em matéria de criação eu acredito mais no trabalho do que na espontaneidade. Eu não creio que a espontaneidade seja critério de nada. (...) 0 que eu faço espontaneamente não presta, me dá a impressão de que é eco de alguma coisa que eu li ou eco de outra pessoa. Eu acho que a pessoa é autêntica quando trabalha demais para eliminar, daquilo que ela faz, tudo que não é ela mesma, tudo que é estranho. Eu acho o trabalho essencial na criação artística, e é através do trabalho que a pessoa chega a uma expressão autêntica. 0 espontâneo você não controla, vem de cambulhada (MELO NETO, 1998, p. 32)

Como é possível que dois poetas, com visão e interpretação tão diferentes do ato criador, tenham nos deixado, ambos, uma poesia de tão grande potência e relevância, que revolucionou a lírica brasileira do século XX?

0 fato é que a natureza e o significado do ato poético intrigam, como 
dissemos no início, desde sempre filósofos, psicólogos, antropólogos, críticos e os próprios poetas. Até o século XVIII a criação poética era sinônimo de imitação, imagem ou cópia de uma realidade. Tal interpretação vem da filosofia grega, para Platão (2003) e Aristóteles (1990) poesia é mimesis e decorre da exigência humana de representar e de exprimir por imagens a realidade circundante. A mimese tem, no entanto, para os dois filósofos, diferenças profundas de interpretação. Para Aristóteles essa imitação não pode ser considerada como uma mera cópia de elementos da realidade, mas o modo com o qual o poeta enuncia verdades gerais por meio dos fatos particulares:

Por isso, a Poesia encerra mais filosofia e elevação do que a História; aquela enuncia verdades gerais; esta relata fatos particulares. Enunciar verdades gerais é dizer que espécie de coisas um indivíduo de natureza tal vem a dizer ou fazer verossímil ou necessariamente; a isso visa a Poesia, ainda quando nomeia personagens(ARISTÓTELES, 1990, p. 28).

A poesia tem assim, para Aristóteles, um valor gnosiológico e se aparenta com a filosofia, o que não ocorre para Platão, que vê a mimese poética "como uma brincadeira sem seriedade", o que o leva, na República, a condenar os poetas (PLATÃO, 2003, p. 301). Para Platão, “a arte de imitar está bem longe da verdade, e se executa tudo, ao que parece, é pelo fato de atingir apenas uma pequena porção de cada coisa, que não passa de uma aparição" (PLATÃO, 2003, p. 296). A imitação proporcionaria, assim, um conhecimento limitado e só a filosofia conduziria realmente ao sentido profundo das coisas. Platão ainda é mais radical, ao afirmar que "a arte de imitar só produz mediocridades" (2003, p. 302),

Não obstante essas diferenças profundas de interpretação entre os dois filósofos, é comum em ambos "a noção de que toda a obra poética como toda a obra de arte - tem de manter uma relação de semelhança e de adequação com uma realidade natural já existente" (AGUIAR E SILVA, 1976, p. 145-146). 
A partir da segunda metade do século XVIII, a doutrina da arte como imitação começa a declinar em concomitância com a valorização crescente da figura do artista. De fato, no Romantismo, a atenção se desloca do objeto a ser representado para o sujeito que o representa e o poema passa a ser visto como expressão de sentimentos, desejos e sonhos, uma revelação da interioridade do autor. 0 ato de criar adquire um grande valor: o poeta participa da gênese, plasma um mundo alternativo ao da realidade exterior, revela o ser humano pelo lado de dentro, com seus mistérios. Dessa forma, o poeta se torna uma espécie de vidente, pois consegue penetrar no sentido oculto de seres e coisas. Em relação à poesia vista como mimese, em que o texto mantém ligação com o mundo externo, essa nova concepção da arte poética propicia maior liberdade aos autores, solta a fantasia, promove e solicita a criatividade. Ela, no entanto, quando bem analisada, não se distancia da ideia de que a obra de arte é tradução fiel do mundo, com a diferença de que, agora, não é mais o mundo objetivo que interessa, mas o da subjetividade dos criadores.

Essa mudança nos postulados da poética está intimamente relacionada às transformações profundas causadas pela Revolução Industrial, que contribuiu para consolidar, em todo o mundo ocidental, o capitalismo, marcando, de fato, a passagem do capitalismo mercantil para o industrial. Surge a economia de mercado, que concentra a riqueza, transforma o indivíduo em produtor e consumidor de mercadorias, desumaniza o trabalho, aumenta a disparidade social, converte a natureza em fonte de matéria-prima para alimentar a fome constante de novos produtos e para satisfazer o mercado.

Se, no século XIX, o poeta reage a esse aviltamento das relações sociais e à dessacralização da natureza, reafirmando o valor subjetivo do eu lírico e até mesmo supervalorizando a sua individualidade; no século XX, a reação foi oposta e houve o que Nuno Júdice (1998) chamou de "radical eutanásia" do subjetivo na poesia, ou seja, "se eliminou do horizonte a figura do Autor, transferindo para o corpo do texto - as palavras - tudo aquilo que esse conceito arrastava" (JÚDICE, 1998, p. 43). 
0 resultado foi uma poesia que renunciou não apenas à expressão dos sentimentos e à introspecção psicológica, mas também a qualquer tentativa de relacionar a literatura com a sociedade e com a história. A poesia voltou-se para si mesma, tornando-se autorreferencial, poesia que indaga sobre a sua própria natureza e que é metalinguagem (muito embora essa mesma atitude seja uma resposta histórica à marginalização crescente da figura do poeta). A aparente aridez da poesia contemporânea é também um modo de resistir:

Essas formas estranhas pelas quais o poético sobrevive em meio hostil ou surdo, não constituem o ser da poesia, mas apenas o seu modo historicamente possível de existir no interior do processo capitalista. (...) A poesia, reprimida, enxotada, avulsa de qualquer contexto, fecha-se em um autismo altivo; e só pensa em si, e fala dos seus códigos mais secretos e expõe a nu o esqueleto a que a reduziram; enlouquecida, faz de Narciso o último deus(BOSI, 1977, p. 143).

Atualmente, essas formas extremas de resistência convivem com outras, em que a poesia ou se reapropria da dimensão social, com um retorno às formas do realismo (que não significa representação mecânica do real), ou retoma a dimensão do símbolo, do sonho, da memória, do inconsciente e do mito. A estética contemporânea reconhece, assim, a conexão inegável com o tempo e com o espaço em que se situa o artista ou o escritor, mas considera que a poesia é, em absoluto, criação, invenção, presentificação e não somente representação do real. A arte e a poesia revelam aspectos originais e inusitados do mundo, frequentam dimensões complexas e profundas do ser e do universo que nos rodeia.

Ocorre esclarecer, aqui, um elemento importante, que desde sempre tem gerado confusão nos leitores: o eu lírico poético não se confunde com o eu biográfico do poeta, poesia não é confissão, não é reprodução da interioridade do autor ou de elementos da sua vida, embora, é certo, suas experiências acabem por confluir na obra literária. Isso não quer dizer, também, que a palavra poética dissimule, aliene, falseie ou distan- 
cie autor e leitor da matéria factual da vida, objetiva ou subjetiva. 0 que se verifica é que, por meio da poesia, habitamos o mundo, deixamos o limite do nosso corpo para adentrarmos no outro, tornarmo-nos o outro, vivermos a experiência da alteridade e retornarmos estranhados de nós mesmos. $\mathrm{O}$ eu lírico hospeda e congrega em si, na primeira pessoa, seres de tempos e espaços diversos com os quais o poeta, com sua capacidade de pôr-se em escuta, estabelece uma relação empática.

No ato de escrita, afirma David Grossman (2007), o escritor projeta a sua psique na do personagem que está criando. Se isso é válido para a prosa, certamente o é, e talvez de forma ainda mais radical, para a poesia. Nessa busca de simbiose, o escritor tenta se libertar do vínculo do seu próprio ser para chegar ao centro da identidade do outro, sem convertê-la à sua subjetividade, sem inibi-la ou subjugá-la a priori. Em tal movimento, o escritor não apenas assimila a alteridade, mas, por meio dessa deslocação estranhante, revela a si mesmo aspectos desconhecidos de sua personalidade. No belíssimo ensaio Conoscere l'altro dal di dentro, o escritor israelense narra tal processo, misterioso e alquímico, que é a própria razão e o sentido profundo da literatura:

[...] quando chego a tal consciência do outro, pelo lado de dentro, [...] vivo então um dos grandes prazeres que a escritura possa proporcionar: a faculdade de permitir aos meus personagens serem eles mesmos, dentro de mim. 0 escritor tornase, então, o espaço no qual os seus personagens podem realizar características e aspirações e ações, impulsos e coisas loucas, desviantes ou santas, das quais o escritor não seria capaz [...]. Que milagre, que felicidade, que doce recompensa são tais momentos, quando, durante o trabalho de escritura de um determinado personagem o escritor é por este reescrito: ou seja, uma nuança desconhecida do seu caráter, que estava muda, latente, reprimida, formula-se de repente, é 'resgatada' por um dos seus personagens, 'vem à luz' no sentido literal da expressão(GROSSMAN, 2007, p. 20-21) 2 .

${ }^{2}$ Trad.Minha. 
Essas questões foram afrontadas de forma genial por Fernando Pessoa (1985), um dos poetas mais conscientes do peculiar "fingimento" poético, transformado em indagação fenomenológica ao longo de sua obra. Pessoa confessou, em vários poemas e cartas, que foi profundamente sincero em seus heterônimos, pois cada um deles desenvolveu uma propensão e uma dimensão diferente da sua personalidade. Ele pulverizou a ideia de um eu lírico unitário, coerente e coeso, correspondente ao eu autoral, e daí deriva a dificuldade de identificar qualquer dos heterônimos com o indivíduo Fernando Pessoa. Realizando essa viagem introspectiva pelos meandros do ser, ele alargou a consciência, iluminou ângulos obscuros e misteriosos da nossa mente, navegou por espaços e dimensões do incognoscível:

Isso é toda uma literatura que eu criei e vivi, que é sincera, porque é sentida, e que constitui uma corrente com influência possível, benéfica incontestavelmente, nas almas dos outros. 0 que eu chamo literatura insincera não é aquela análoga à do Alberto Caeiro, do Ricardo Reis, ou do Álvaro de Campos [...]. Isso é sentido na pessoa do outro; é escrito dramaticamente, mas é sincero (no meu grave sentido da palavra) como é sincero o que diz o Rei Lear, que não é Shakespeare, mas uma criação dele. Chamo insinceridade às coisas feitas para fazer pasmar, e às coisas, também - repare nisto porque é importante - que não contêm uma fundamental idéia metafísica, isto é, por onde não passa, ainda que como um vento, uma noção da gravidade e do mistério da Vida. Por isso é sério tudo o que escrevi sob os nomes de Caeiro, Reis, Álvaro de Campos. Em qualquer destes pus um profundo conceito da vida, divino em todos três, mas em todos gravemente atento à importância misteriosa de existir (PESSOA, 1985, p. 53).

A poesia é, como se pode ver, um potente canal de conhecimento, aliás, poesia é gnosis. 0 poeta é um pesquisador de tipo especial, seu campo de indagação e análise tem como objeto o humano, o ser em sua totalidade e abrangência, indivisível de corpo e espírito, de carne e consciência. 0 cientista perquire a matéria animada e inanimada, as leis que governam 
o movimento, a substância e a energia da vida. 0 poeta, ao contrário, indaga a consciência e o seu outro lado, pesquisa o ser humano no tempo e na história, embora lhe interesse também - e talvez até mais - o antes, o além e o depois do tempo histórico; o poeta quer entender a gênese e as consequências da dor, do mal, do trágico, como também o eclodir do sentimento amoroso, da alegria e da esperança no coração dos homens. 0 poeta sonda e ronda até os limiares da consciência, tenta alargar essa fronteira, realizando viagens verticais e forçando a língua, as línguas, a articular o indizível. É uma viagem em que ele põe em jogo a sua vida.

0 poeta é capaz de olhar e ver o mundo e os seres como se fosse sempre a primeira vez e, com esse olhar estranhado e atônito, ele colhe o insólito no que é corriqueiro e o eterno no que é, por sua natureza, mortal. Afirma a poetiza portuguesa Sophia de Mello Breyner Andresen (1985), em um texto intitulado Arte Poética II, de 1967:

A poesia não me pede propriamente uma especialização pois a sua arte é uma arte do ser. Também não é tempo ou trabalho o que a poesia me pede. Nem me pede uma ciência nem uma estética nem uma teoria. Pede-me antes a inteireza do meu ser, uma consciência mais funda do que a minha inteligência, uma fidelidade mais pura do que aquela que eu posso controlar. [...] Pede-me que viva atenta como uma antena, pede-me que viva sempre, que nunca me esqueça. Pede-me obstinação sem tréguas, densa e compacta. [...] o poema fala não de uma vida ideal mas sim de uma vida concreta [...]. É esta relação com o universo que define o poema como poema, como obra de criação poética. Quando há apenas relação com a matéria há apenas artesanato (ANDRESEN, 1985, p. 223).

Poesia é, pois, integridade e totalidade do ser, enquanto que a cultura da modernidade, afirma Nize Maria Campos Pellanda (2012), configurada a partir do paradigma cartesiano, calcada nas fragmentações da realidade, relegou as práticas de constituição de si e as auto-narrativas "a estatutos de menor importância na vida dos homens e mulheres" (CAM- 
POS PELLANDA, 2012, p. 129). A estudiosa acrescenta ainda que as cisões impostas por esse paradigma cartesiano, corpo/mente, conhecer/ viver, texto/leitor, interpretação/constituição, "vão se impondo, numa cadeia sem fim, acabando por esvaziar o sujeito moderno de suas potencialidades constituintes e configurando uma cultura empobrecida e esvaziada das dimensões existenciais" (PELLANDA, 2012, p. 129).

No entanto, nunca tivemos tanta necessidade de poesia como nesse nosso tempo alienante, pois a poesia proporciona, como dissemos, uma forma de conhecimento interior muito profundo, um conhecimento em muitos casos alternativo em relação às categorias racionais do conhecimento. Tal experiência tem o poder de mudar completa e radicalmente a nossa vida, de emancipá-la dos limites de espaço e tempo, de gerar a sensação - como afirma Ezra Pound - de crescimento repentino, que experimentamos diante das obras de arte (POUND, 1976, p. 11).

Para Octavio Paz (1976), a poesia, "mesmo na coincidência, é dissidência". E acrescenta: "afirmo que a poesia é irredutível às ideias e aos sistemas. É a outra voz. Não a palavra da história nem a da anti-história, mas a voz que, na história, diz sempre outra coisa - a mesma desde o princípio" (PAZ, 1976, p. 153.) Tentando esclarecer essas palavras, ele afirma: "Não sei como defini-la sem explicar em que consiste essa diferença, esse tom que, sem isolá-la, torna-a única e distinta. Direi apenas que é uma estranheza e a familiaridade em pessoa. Basta ouvi-la para reconhecê-la" (PAZ, 1976, p. 153.)

Nesse ponto são naturais as perguntas: que instrumentos o poeta utiliza nessa busca visceral? Que tipo de conhecimento proporciona a poesia? Sobre essas questões pregnantes se debruçaram filósofos e estudiosos das várias áreas do saber humano. Possuímos também um rico manancial de reflexões, descrições e análises produzidas pelos poetas, sempre mais conscientes do próprio ofício e, muitos deles, críticos e professores universitários de literatura ou de teoria da literatura. Tomo aqui o testemunho de Nuno Júdice (que dedicou ao tema o livro As máscaras do poema(1998)). Para o autor português, a poesia existe "numa 
zona de que o pensamento, ou pelo menos o pensamento lógico, racional, parece estar ausente ou ser desnecessário" (JÚDICE, 1998, p. 39). 0 próprio objetivo da poesia se realiza numa dimensão que ultrapassa o aspecto lógico. Ele afirma também que

se integrarmos a poesia dentro do fenômeno criativo como um dos aspectos da expressão estética do humano, já se torna possível uma outra formulação: pensar o poético. A poesia corresponde a uma actividade que se integra nesse acto de produção de um corpo de palavras organizado segundo leis específicas e que obedece a um cânone imemorial; e existe num segmento da actividade humana que tem a ver com o mito, o sagrado, o inexplicável, daí retirando uma parte do seu fascínio e da sua especificidade(JÚDICE, 1998, p. 39).

Outro poeta e crítico, Décio Pignatari (1977), nos dá indicações mais precisas sobre a natureza do pensar poético, quando afirma que:

[...] o pensamento lógico tende a dividir as coisas em partes; o pensamento analógico a mostrá-las em conjunto, como um todo. 0 pensamento lógico trabalha com unidades discretas, ou seja, separadas (letras, números); o analógico, com realidades contínuas(PIGNATARI, 1977, p. 51).

A poesia, a música, o desenho, as artes em geral são configurações do pensamento analógico, que é - ele afirma - "o pensamento das formas" (IDEM, p. 50-51). Temos aqui, portanto, um das contradições da poesia, ela é um corpo analógico dentro de um corpo lógico, representado pela língua (IDEM, p. 53). Não é o único paradoxo, a poesia abraça os opostos, vida e morte, tempo e eternidade, tensão e plenitude, salvação e abandono, participação e alheamento, epifania do sacro e consciência da finitude do humano.

Por situar-se no campo do sensível, por ser um pensamento capaz de sentir, por ser um sentimento pensante, não podemos renunciar à poesia, não obstante constatemos, a cada dia, que ela não tem mais lugar 
nem função na sociedade e, talvez, por ser a outra voz da história, por ser a voz que não coincide com a história, como afirma Paz, ela nunca foi realmente aceita.

Afirma o psiquiatra italiano Eugenio Borgna (2011) que não "seria possível colher as raízes de experiências emocionais, como a da solidão e a do silêncio, sem as grandes intuições poéticas” (BORGA, 2011, p. 114). Em seus livros de psiquiatria fenomenológica, ele dedica partes inteiras à poesia, analisando textos de Francesco Petrarca, Giacomo Leopardi, Emily Dickinson, Rainer Maria Rilke, Antonia Pozzi e outros, para colher, neles, limites insondáveis da nossa interioridade, um conhecimento emotivo profundo e complexo que seria inalcançável pela simples pesquisa e observação racional. Acrescenta, refletindo sobre a experiência dos grandes poetas e místicos, como Teresa d’Avila, Juan de la Cruz, Ângela da Foligno, Blaise Pascal, que ela proporciona uma forma de conhecimento "outro", intuitivo, radicalmente diferente do conhecimento racional, mas, ao mesmo tempo, extremamente complexo e abrangente (BORGNA, 2009, p. 126-127).

No livro A banalidade do mal, de Hannah Arendt (2010), em que ela relata o processo a Adolf Eichmann, realizado em 1961, em Jerusalém, os juízes afirmaram que a tragédia vivida por milhões de judeus atingia uma escala tão gigantesca que ultrapassava a própria capacidade de entendimento humano e que era, por isso, matéria para grandes poetas e escritores (ARENDET, 2010, p. 218). Nesse sentido, Hannah Arendt concorda com a proposição, ao afirmar que só mesmo "no reino transfigurador da poesia" é possível narrar tanto mal e dor (IDEM, p.236).

No livro, Se questo è un uomo, Primo Levi (1987) desce ao inferno do campo de concentração nazista, expõe a língua e suas sílabas ao abjeto, à degradação do humano, ao horror que ele e milhões de outros homens atravessaram. Levi, de origem hebraica, foi preso em dezembro de 1943, em Milão, e mandado para o campo de concentração de Carpi-Fóssoli e, a seguir, para o de Auschwitz. A memória de tal experiência o acompanhará até a morte trágica, em 1987. Narrar essa imersão no mal absoluto, o 
atravessamento dos limites humanos da dor física e moral, se tornou a razão de sua vida. Se questo è un uomo, escrito em 1946, é um dos livros mais trágicos e, ao mesmo tempo, mais poéticos da literatura do século $\mathrm{XX}$ :

Então pela primeira vez percebemos que à nossa língua faltam palavras para exprimir esta ofensa, a demolição de um homem. Em um instante, com intuição quase profética, a realidade se nos revelou: chegamos ao fundo. Mais baixo do que estamos, não podemos ir: condição humana mais miserável não há, e não é pensável. Nada mais é nosso: tiraram nossas roupas, os sapatos, também os cabelos; se falarmos, não nos ouvirão, e se nos ouvissem, não nos entenderão. Tirarão até o nosso nome: e se quisermos conservá-lo, deveremos encontrar em nós a força para fazê-lo, para fazer com que, atrás do nome, ainda algo de nós, de nós como éramos, permaneça (LEVI, 1987, p. 20)3.

Levi não foi o único grande escritor a narrar a experiência dos campos de extermínio, outros o fizeram e entre eles PaulCelan (1998), pseudônimo de Paul Antschel. Nascido em Czernowitz (Bucovina, na Romênia, hoje Ucrânia), de família judeu-alemã, teve os pais deportados e foi, ele também, preso e obrigado aos trabalhos forçados entre 1942 e 1943. Libertado pelos soviéticos, em 1945, Celan abandona Czernowitz em direção à Bucareste, depois Viena e, por fim, Paris, cidade onde permaneceu até o suicídio, em 1970.

Em "Fuga da morte" (ano), um dos seus poemas mais famosos, Celan vive o lacerante dissídio interior de tentar representar, pela linguagem, o inominável de uma experiência, para a qual não há palavras capazes de contê-la em toda a sua dimensão trágica.Não só quis fazê-lo em alemão, por ser a língua dos seus algozes, mas também por ser a sua línguamãe, o código do amor mais puro e do ódio mais atroz, que ele vivenciou, como milhões de outros que sucumbiram sem poder testemunhar tal tragédia. Nos versos de Celan, o alemão é desarticulado, sílaba por sílaba, é decomposto até o balbucio, o gemido e, por fim, o silêncio. A sua

${ }^{3}$ Trad. minha. 
poesia marca a fogo a língua em que foi escrita, a que serviu aos nazistas na cega fúria de domínio, a que plasmou a palavra das vítimas, degradadas, espoliadas de tudo e emudecidas para sempre:

Leite negro da madrugada nós o bebemos de noite nós o bebemos ao meio-dia e de manhã nós o bebemos de noite nós o bebemos bebemos cavamos um túmulo nos ares lá não se jaz apertado Um homem mora na casa bole com cobras escreve escreve para a Alemanha quando escurece teu cabelo de ouro Margarete escreve e se planta diante da casa e as estrelas faíscam ele assobia para os seus mastins assobia para os seus judeus manda cavar um túmulo na terra ordena-nos agora toquem para dançar

(...)

Leite negro da madrugada nós te bebemos de noite nós te bebemos ao meio-dia a morte é um dos mestres da Alemanha

nós te bebemos de noite e de manhã nós bebemos bebemos a morte é um dos mestres da Alemanha seu olho é azul acerta-te com uma bala de chumbo acerta-te em cheio um homem mora na casa teu cabelo de ouro Margarete ele atiça seus mastins sobre nós e sonha a morte é um dos mestres da Alemanha teu cabelo de ouro Margarete teu cabelo de cinzas Sulamita (CELAN, 1998, trad. de Modesto Carone).

Sobre a poesia possível e necessária da desarticulação do humano, sobre essa transformação de "uma impossibilidade lógica em uma possibilidade estética”, escreveu Giorgio Agamben (2010), em Quel che resta di Auschwitz, afirmando: "Não o poema ou o canto podem atuar para salvar o impossível testemunho, ao contrário, é o testemunho que pode, eventualmente, fundar a possibilidade do poema”"(AGAMBEN, 2010, p. 33).

\footnotetext{
4 "Non il poema o il canto possono intervenire a salvare l'impossibile testimonianza; al contrario, è la testimonianza che può, semmai, fondare la possibilità del poema" (AGAMBEN, 2010, p. 33).
} 
Para Adorno (1984), depois de Auschiwitz a poesia não é mais possível. Levi e Celan demonstram o contrário: depois de Auschiwitz, só a poesia foi possível, a poesia como linguagem capaz de conter o sentimento de aniquilamento total, de acompanhar uma consciência dentro da noite, de atravessar esse limiar e de permitir o retorno ao mundo dos homens. Afirma Primo Levi (1987), "Escrevia poesias concisas e ensanguentadas, narrava com vertigem, em voz alta e por escrito, tanto que pouco a pouco nasceu o livro: escrevendo, encontrava momentos breves de paz e senti que voltava a ser de novo homem" (LEVI, 1987, p. 45).

As palavras poéticas de Celan e Levi se condensam com tal intensidade que não apenas revelam, iluminam e ordenam o caos desumanizador, mas salvam, reintegram, transcendem e elevam; resvalam as fímbrias inomináveis do nada absoluto e da morte, para além da qual nenhum poeta pode penetrar com uma língua humana.

\section{REFERÊNCIAS}

ADORNO, T. W. Aesthetics Theory. London: Routledge \& Kegan Paul, 1984.

AGAMBEN, G. Quel che resta di Auschwitz. Torino: Bollati Boringhieri, 2010

AGUIAR E SILVA, V. M. de. Teoria da literatura. São Paulo: Livraria Martins Fontes Editora, 1976.

ARENDET, H. La banalità del male. 17 ed. Trad. di P. Bernardini, Milano: Feltrinelli,.2010

ARISTÓTElES, HORÁCIO, LONGINO.. A poética clássica. 4 ed. Trad. de Jaime Bruna, São Paulo: Cultrix, 1990 
BANDEIRA., M. Itinerário de Pasárgada. 3 ed.Rio de Janeiro: Nova Fronteira. Brasília: I.N.L., 1984

BORGNA, E. Le emozioni ferite. Milano: Feltrinelli, 2009.

La solitudine dell'anima. Milano: Feltrinelli, 2011.

BOSI, A. 0 ser e o tempo da poesia. São Paulo: Cultrix, Editora da Universidade de São Paulo, 1977.

MELO NETO, J.;ANDRADE, F. de. Idéias fixas de João Cabral de MeloNeto. Rio de Janeiro: Nova Fronteira, Mogi das Cruzes: Universidade de Mogi das Cruzes, 1998

PELLANDA, N. M. Narrativas e constituição de si: a leitura como dimensão eutopoiética, in PIAZZA GAI, E.; OLIVEIRA, V. L. de, Narrativas brasileiras contemporâneas em foco, Editora Universidade Federal de Santa Maria, Santa Maria, 2012.

CEIA, C. (Coord.). E-Dicionário de termos literários. CETAPS (Center for English, Translation and Anglo-Portuguese Studies). Disponível em http://www.edtl.com.pt, 2011.

CELAN, P. Poesie.1 ed. Trad. e cura di G. Bevilacqua. Milano: Arnoldo Mondatori Editore, I Meridiani, 1998.

COUTO, M. Da cegueira colectiva à aprendizagem da insensibilidade, conferência proferida na Faculdade de Artes e Comunicação da Universidade Mondlane, Maputo, 2012.

CRUZ, E.(Org.)O que é a poesia? Rio de Janeiro: Confraria do Vento: Calibán, 2009.

GROSSMAN, D. Con gli occhi del nemico. Trad. di E. Loewenthal e A. Shomroni. Milano: Mondatori,2007. 
IVO, L.O vento do mar, Rio de Janeiro: Academia Brasileira de Letras e Contra Capa, 2011.

JAKOBSON, R. Lingüística e comunicação. 9 ed.Trad. de Izodoro Blikstein e José Paulo Paes, São Paulo: Editora Cultrix, 1977.

JOLY, M. A imagem e os signos. Trad. de Laura Carmo Costa e Verbis Ibéria, Lisboa: Edições 70, 2005.

JÚDICE, N. As máscaras do poema. Lisboa: Aríon Publicações,1998.

LEVI, P. Se questo è un uomo.Opere, Volume primo. Torino: Giulio Einaudi Editore,1987.

LEVIN, S. R. Estruturas lingüísticas em poesia. Trad. de José Paulo Paes, São Paulo: Cultrix, Editora da Universidade de São Paulo, 1975.

ANDRESEN, S. Arte Poética II, Antologia. Porto: Figueirinhas, 1985.

OLIVEIRA, V. L. de. 0 eu e o outro na tradução: pensando a alteridade. O Brasil e seus tradutores, número monográfico de Ipotesi,Revista de Estudos Literários, Juiz de Fora: Editora da Universidade Federal de Juiz de Fora, jan./jul., v. 13, n. 1, p. 81-86,2009.

PAZ, O. Signos em rotação. 2 ed.Trad. de Sebastião Uchoa Leite. São Paulo: Editora Perspectiva, 1976.

------. 0 arco e a lira. Trad. de Olga Savary. Rio de Janeiro: Nova Fronteira, 1982.

PESSOA, F. Obras em prosa. Org de Cleonice Berardinelli. Rio de Janeiro: Editora Nova Aguilar, 1985.

PIGNATARI, D. Comunicação poética. São Paulo: Cortez \&Moraes, 1977. 
PLATÃO. A república. Trad. de P. Nassetti. São Paulo: Editora Martin Claret, 2003.

POUND, E. A arte da poesia: ensaios escolhidos. Trad. de Heloysa de Lima Dantas e José Paulo Paes. São Paulo: Cultrix, EDUSP, 1976.

SARTRE, J. P. 0 ser e o nada. Trad. Paulo Perdigão. Petrópolis: Vozes, 2002.

SPINA, S. Na madrugada das formas poéticas. 2 ed.Cotia: Ateliê Editorial, 2002. 